\title{
EFECTOS DE CAMPOS MAGNÉTICOS EN EL METABOLISMO Y CRECIMIENTO DE Lactobacillus plantarum
}

\author{
Iván Ramírez Jiménez, Christian Pacheco Espino, Karol Bär Villalobos, \\ Sandra León López, David Enrique Reyes, Yat Sen Wong, \\ Juan Carlos Ramos Gorbeña
}

\begin{abstract}
RESUMEN
En la presente investigación se realizaron el cultivo microbiológico de Lactobacillus plantarum y de preparación de los sistemas de generación de campo magnético alterno de hasta $53 \mathrm{kHz}$. Se logró determinar la influencia del campo magnético variable sobre el crecimiento del Lactobacillus plantarum, observado en las muestras sometidas a campo en tiempos cortos con mediana frecuencia produciendo un aumento en el número de unidades formadoras de colonias - UFC, aproximadamente en un $70 \%$ más comparado con las muestras control.

Para el recuento bacteriano se utilizó agar Plate count marca Merck empleando el método de diseminación en placas de Agar. Para la generación de los campos de inducción magnética de distinta frecuencia, se diseñó, construyo y probo cinco bobinas tipo Helmholtz de diferentes características que producían campos magnéticos estables de hasta $60 \mathrm{KHz}$. en el orden de los miliGauss. La bobina utilizada en la presente investigación tiene un resistencia óhmica de $4.2 \mathrm{ohm}$ y una inductancia de $0,345 \mathrm{mH}$ con 140 espiras bifilar con un alambre awg \# 23.
\end{abstract}

Palabras clave: campos magnéticos alternos, Lactobacillus plantarum, crecimiento, metabolismo

\section{SUMMARY}

In the present investigation microbiological culture of Lactobacillus plantarum and preparation systems generating alternating magnetic field of up to $53 \mathrm{kHz}$ were performed. It was possible to determine the influence of variable magnetic field on the growth of Lactobacillus plantarum, observed in the samples subjected to field in short times with medium frequency causing an increase in the number of colony forming units - UFC, approximately $70 \%$ compared control samples.

Agar for bacterial counts mark Plate count Merck was used method using spread on agar plates. To generate magnetic fields of different frequency induction, was designed, built and tested five different types of Helmholtz coils producing stable features magnetic fields up to $60 \mathrm{KHz}$. in the order of milliGauss. The coil used in this research has an ohm resistance of $4.2 \mathrm{ohms}$ and an inductance of $0.345 \mathrm{mH} 140$ bifilar windings with \# 23 AWG wire.

Keywords: alternating magnetic fields, Lactobacillus plantarum, growth, metabolism.

\section{INTRODUCCIóN}

Uno de los sectores que presenta mayor auge en el Perú, es la industria de lácteos con una tasa anual de crecimiento de 9\%. Dentro de sus derivados son bienes altamente cotizados el queso y el yogurt, que en nuestro país presentan un pujante sector artesanal e industrial en desarrollo. Esta producción se basa en la utilización de bacterias lácticas como Lactobacillus acidophilus y Streptococcus thermophilus, que se valen de su apacidad de desdoblar la lactosa y de fermentar azucares; además poseen propiedades benéficas como el aumento de la capacidad de absorción del sistema digestivo y la producción de bacteriocinas, sustancias proteicas con capacidad inhibidora de otras bacterias 
El estudio de los factores biofísicos involucrados en el proceso biotecnológico de la fermentación y sus consecuencias son de completo interés, estos son; la temperatura, $\mathrm{pH}$, concentración de nutrientes y oxígeno. La velocidad de fermentación del proceso está en una relación directa con el nivel de división y concentración celular, siendo esta característica la principal en los procesos de producción, ya que determinan el nivel de la calidad del producto. Una de las fuerzas que afecta a todo organismo sobre la tierra es el campo magnético, que no puede ser percibido de manera clara, pero tiene gran influencia en los sistemas vivos, debido a la capacidad de alterar el flujo de iones a través de la membrana celular, de re direccionar las biomoléculas y hasta entrar en resonancia con las moléculas inorgánicas. Estos efectos son observables metabólicamente a nivel de un organismo procariota en su división celular y sobre todo en los canales de iones, estructuras proteicas asociadas a la membrana. Para incrementar el conocimiento y aplicabilidad en el campo de la, biotecnología, se ha trabajado en la investigación de los posibles efectos de los campos magnéticos de baja intensidad en el crecimiento y metabolismo de Lactobacllus acidophilus y Lactobacillus plantarum utilizando exposiciones variables de tiempos, con intensidades del orden de miliGauss y de frecuencias en los órdenes de los Khz.

La hipótesis plantaeada de trabajo refiere a que: La exposición de un campo magnético variable de baja intensidad fomentara a una mayor división celular y no afectara al metabolismo de Lactobacillus plantarum con respecto a los expuestos a condiciones normales.

\section{OBJETIVOS}

\section{Objetivo General:}

- Evaluar la influencia del campo magnético de intensidad variable y de baja frecuencia en el crecimiento y metabolismo de Lactobacillus plantarum.

\section{Objetivos Específicos:}

- Determinar el rango de intensidad óptima de campo magnético sobre el crecimiento y desarrollo de Lactobacillus plantarum.

\section{MATERIAL Y MÉTODOS}

\section{Procedimiento Biológico}

Se procedió a la reactivación de la cepa ATCC Lactobacillus plantarum en agar tripticasa soya marca Merck, se incubo a $37^{\circ} \mathrm{C}$ por lapso de 24 horas, luego del tiempo transcurrido se transfirió una colonia a un tubo que contenía $5 \mathrm{~mL}$ de caldo MRS marca se incubo a $37^{\circ} \mathrm{C}$ por 24 horas.

El cultivo control y el experimental de Lactobacillus plantarum tuvieron los mismos factores intrínsecos y extrínsecos (condiciones nutricionales, temperatura, humedad, $\mathrm{pH}$ y el tiempo) para que desarrolle un cultivo joven en condiciones ideales. El cultivo experimental se expuso al campo magnético por un tiempo de 3 minutos. Posterior a la exposición al campo magnético se realizó las diluciones hasta $10 " 13$ y a partir de esta dilución se realizó la siembra en agar plate count marca Merck por el método de diseminación en placas de agar se incubo a $37^{\circ} \mathrm{C}$ por 24 horas. Finalmente se procedió a realizar el recuento de las unidades formadoras de colonias $\mathrm{UFC} / \mathrm{mL}$.

\section{Procedimiento de diseño y construcción de las bobinas}

Se diseñaron las bobinas para la investigación para lo cual se elaboró un software y se construyeron bobinas circulares magnéticas, (figura $\mathrm{N}^{\circ} 1$ y 2) en el laboratorio de Física de la $\mathrm{Fa}$ cultad de Ingeniería, para hacer las pruebas de influencia de campo a distintitas frecuencias.

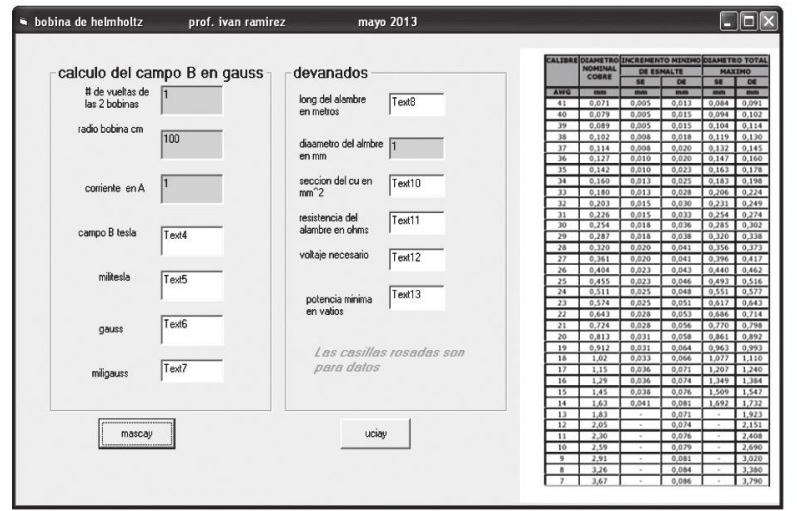

Figura $\mathrm{N}^{\circ} 1$. Software creado para el cálculo aproximado de bobinas 


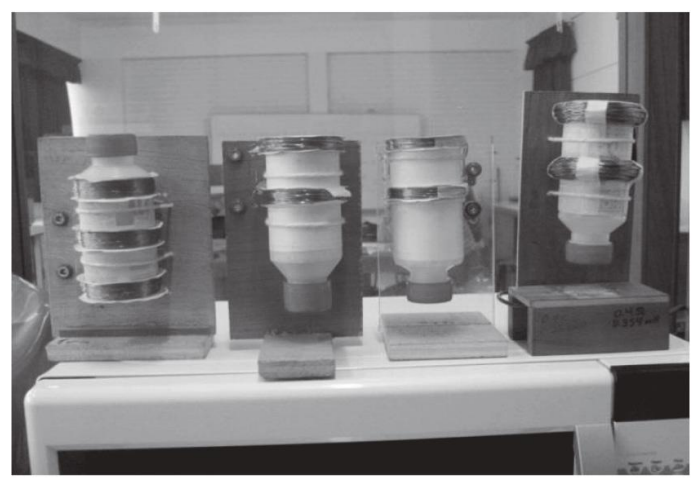

Figura $\mathrm{N}^{\circ}$ 2. Todas las Bobinas diseñadas y construidas para generación de campo B máximo a distintas frecuencias fueron probadas una por una hasta conseguir, la que más alta frecuencia nos daría, y en la que la medición de campo sea estable

Tabla 1. Resultados de las primeras bobinas tipo Helmholtz diseñadas y construidas en el 2013

\begin{tabular}{|c|c|c|c|c|c|c|c|c|}
\hline Bobina \# & \# awg & \# de vueltas & \# de bobinas & $\begin{array}{l}\text { Diámetro } \\
\mathrm{cm}\end{array}$ & $\begin{array}{l}\text { Resistencia } \\
\text { Ohms }\end{array}$ & $\begin{array}{l}\text { Inductancia } \\
\text { en } \\
\text { milihenrios }\end{array}$ & $\begin{array}{l}\text { Max Rango de } \\
\text { frecuencia en } \\
\text { Khz }\end{array}$ & \# de conductores \\
\hline 1 & 32 & 196 & 3 & 5.25 & 51.6 & & $1-10$ & Unifilar \\
\hline 2 & 32 & 400 & 2 & 5.25 & 32.6 & 6.05 & $10-15$ & Unifilar \\
\hline 3 & 21 & 100 & 2 & 5.25 & 1.2 & 0.415 & $10-30$ & Unifilar \\
\hline 4 & 21 & 24 & 2 & 5.25 & 0.3 & 0.101 & $10-20$ & Unifilar \\
\hline 5 & 21 & & 2 & & 0.4 & 0.354 & $20-60$ & Doble \\
\hline 6 & - & - & - & - & - & & & \\
\hline
\end{tabular}

Se ha logrado a diseñar y construir varias bobinas que funciona muy bien entre las frecuencias de $10-53 \mathrm{KHz}$, en el caso de las bobinas de más de $60 \mathrm{KHz}$ el campo presenta mucha inestabilidad.

Se calibraron los campos magnéticos alternos producidos dentro de las bobinas mediante el método de extrapolación de funciones exponenciales (figura $\mathrm{N}^{\circ} 3$ y 4) ya que el equipo del que disponemos tiene un rango max. Limitado de medida de la inducción magnética.

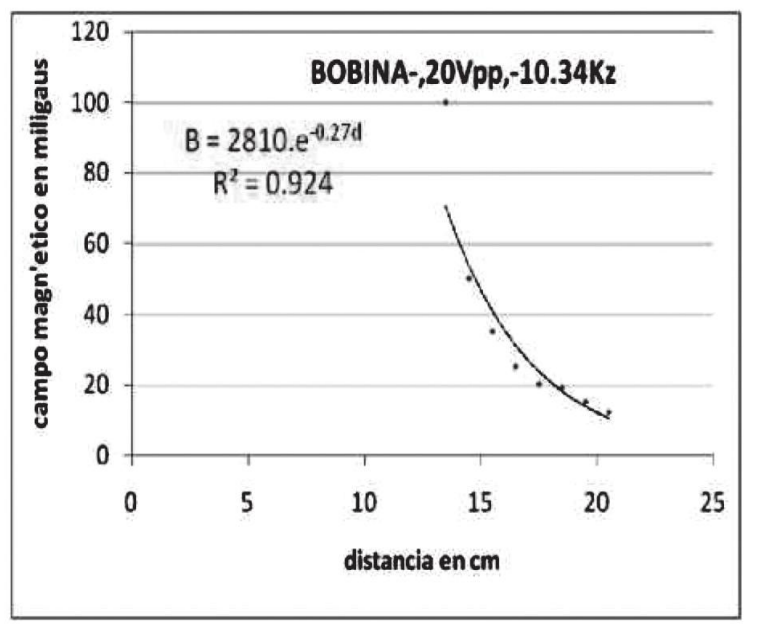

Figura $\mathrm{N}^{\circ}$ 3. Calibración de los campos magnéticos producidos por la bobinas, por el método de extrapolación de curvas.

El campo en el interior es aproximadamente $908 \mathrm{mG}$. 


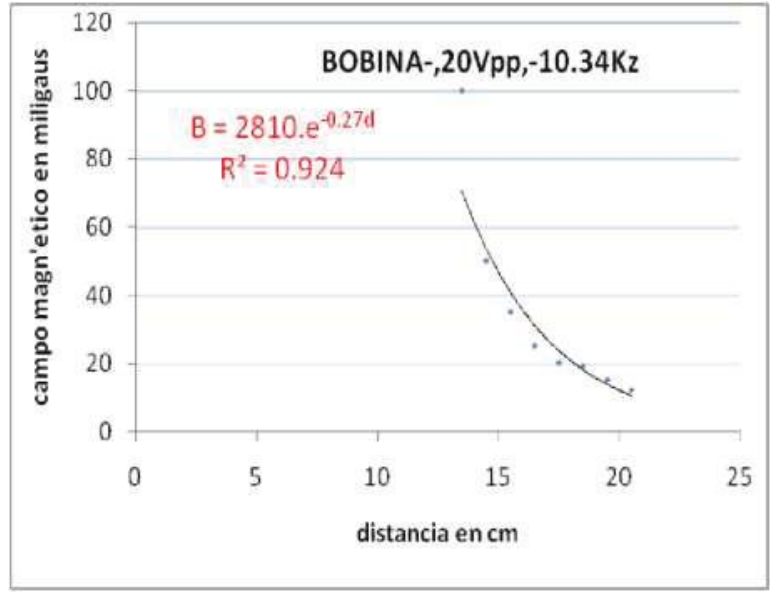

Figura $\mathrm{N}^{\circ} 4$ Calibración de los campos magnéticos producidos por la bobinas, por el método de extrapolación de curvas.

El campo en el interior es aproximadamente 2810 $\mathrm{mG}$

\section{RESULTADOS}

Para la generación de los campos de inducción magnética de distinta frecuencia, se diseñaron, construyeron y probaron cinco bobinas tipo Helmholtz de diferentes características que producían campos magnéticos estables hasta $60 \mathrm{KHz}$. en el orden de los miliGauss.

La influencia del campo magnético variable en el crecimiento del Lactobacillus plantarum sometidas a campo en tiempos cortos y mediana frecuencia en una de las bobinas ha reportado un recuento de unidades formadoras de colonia en promedio al 70\% en comparación con el recuento control. Esta diferencia se ha podido obtener durante tres siembras, consecutivas con e mismo procedimiento metodológico (Figura $\mathrm{N}^{\circ} 5$ y 6 )

Figura $\mathrm{N}^{\circ} 5$. Recuento de Unidades Formadoras de Colonia UFC/mL
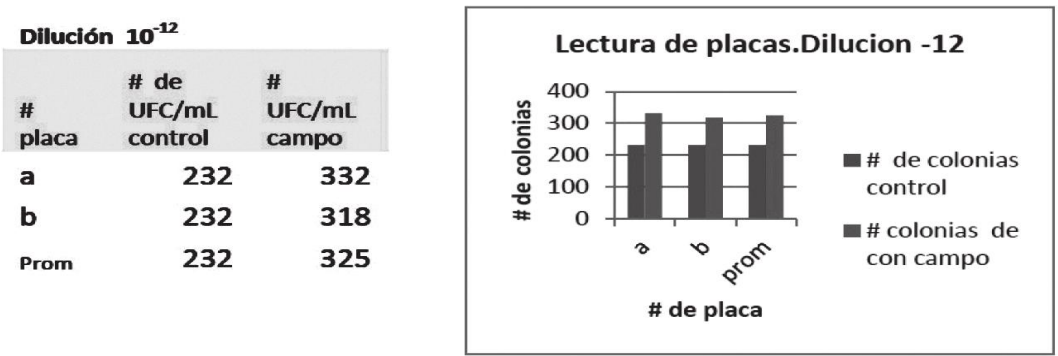

Figura $\mathrm{N}^{\circ} 6$. Recuento de Unidades Formadoras de Colonia UFC/mL

\begin{tabular}{lrr}
\multicolumn{2}{c}{ Dilución } & \multicolumn{1}{l}{$\mathbf{1 0}^{-12}$} \\
& $\begin{array}{l}\text { \# de } \\
\text { UFC/mL }\end{array}$ & \multicolumn{2}{l}{ UFC/mL } \\
\# placa & control & \multicolumn{2}{c}{ campo } \\
a & 27 & 58 \\
b & 14 & 53 \\
c & 41 & 73 \\
Prom & 29 & 61.3
\end{tabular}

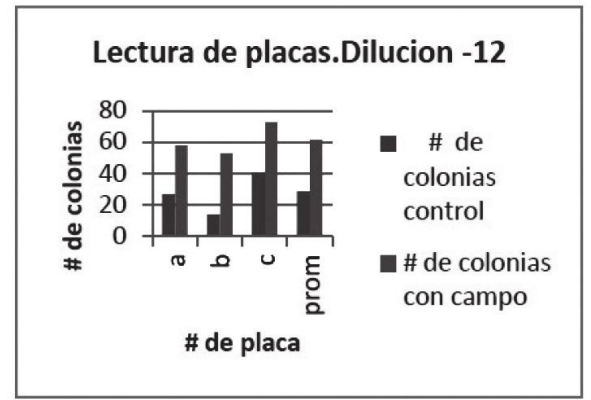




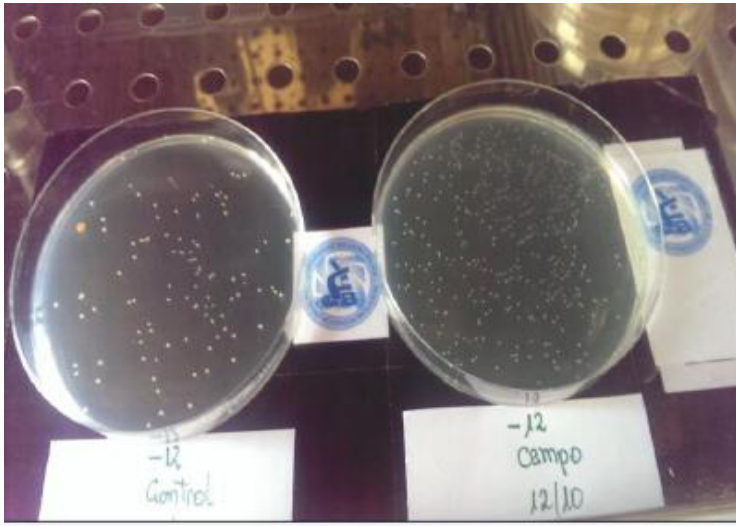

Figura. $\mathrm{N}^{\circ}$ 7. Crecimiento de Lactobacillus plantarum, lado izquierdo control y lado derecho expuesto a campo magnético.

\section{DISCUSIóN}

Considerando que no hemos podido disponer de referencias en otros trabajos exactamente en cepas de Lactobacillus sometidos a campos magnéticos, pero si con respecto a otro tipo de bacterias, que también presenta propiedades de fermentación, como es el caso de "Efectos de los campos magnéticos sobre el crecimiento de Saccharomyces cerevísiae" desarrollado por Zapata, M y otros. Que muestran la influencia de algunas frecuencias de campos magnéticos variables del orden de los $\mathrm{KHz}$ en el desarrollo de Saccharomyces cerevísiae. Podemos afirmar que en la presente investigación, hemos podido determinar que en pruebas consecutivas de recuento bacteriano para Lactobacillus plantarum, la acción de un campo magnético variable dentro del rango de $50 \mathrm{KHz}$, perpendicular al campo magnético terrestre, con intensidad de 100 miliGauus, las muestras de Lactobacillus plantarum expuestas a disparos de una duración de 180 segundos, dentro de una bobina especialmente diseñada con la configuración Helmholtz, ha mostrado una fuerte influencia del campo de inducción magnética, generando desarrollos sorpresivos de Lactobacillus plantarum, que de acuerdo a los resultados experimentales y los cálculos realizados (figuras $\mathrm{N}^{\circ} 5$, 6 y 7) se tienen un incremento del más del $70 \%$. Lo que significa que la velocidad de desarrollo de la fermentación, casi se ha duplicado en el mismo tiempo comparado con las muestras no expuestas al campo, a las que nosotros denominamos control. $\mathrm{Si}$ estos resultados se volverían a repetir en trabajos siguientes la hipótesis quedaría completamente probada, y luego se perfilaría una siguiente investigación a nivel de aplicación en un prototipo de proyección industrial.
Es menester considerar que los resultados obtenidos, es el fruto del esfuerzo, de haber considerado y probado tres métodos para desarrollo de las colonias de bacterias, solo con el tercer método utilizando agua peptonada y con diluciones hasta 10-12 se ha llegado a los resultados que se está reportando.

\section{AGRADECIMIENTOS}

Agradecer de manera especial al Ing. Víctor Zapata Canepa y al Sr. Fernando Torres del Laboratorio de Física de la Facultad de Ingeniería de la Universidad Ricardo Palma por el apoyo y las facilidades brindadas para la realización de la presente investigación.

\section{REFERENCIA BIBLIOGRÁFICA}

LIBOFF, A.; STRONG, T.; WISTAR, D. 1984. R. Time -Varying Magnetic Fields: Effect on DN A Synthesis. Science 223:818-820.

DIHEL, L.; SMITH - SONNEBORN J.; RUSSELL, C. 1985. Effects of and extremely low frequency electromagnetic field on the cell division rate and plasma membrane of Paramecium tetraurelia. Bioeletromagnetics 6:61-71.

MAIKO, J; CONSTANTINIDÍS, I.; DILLEHAY, W. 1994. Fajman Seach for influences of 1. S Tesla Magentic Field on growth of Yeast cell. Bioelectromagnetics. 15: 495-501.

GOLDSWORTHY, A.; WITHNEY, H.; MORRIS, E. 1999. Biological effects of physiclly conditioned water. Wat Res. vol 33,No 7, pp 16181626. 
ZHADIN, N. 2001. Review of Russian Literature on biological action of DC and Low frequency AC Magnetic fields. Bioelectromagnetics 22:2745.

ZAPATA, M.; MORENO, G.; MÁRQUEZ, E. 2002. Efectos de los campos magnéticos sobre el creci- miento de Saccharomyces cerevísiae. Interciencia. Vol. 27, num. 10.

LEDNIEV, V. 1996. Bioefects of weak combined, constant and variable magnetic fields. Biophysics. vol. 41. Pag. 241-252 